Chapman University

Chapman University Digital Commons

2-21-2013

\title{
Household Task Delegation Among High-Fertility Forager- Horticulturalists of Lowland Bolivia
}

\author{
Jonathan Stieglitz \\ University of New Mexico \\ Michael Gurven \\ University of California, Santa Barbara \\ Hillard Kaplan \\ Chapman University, hkaplan@chapman.edu
}

Paul L. Hooper

University of New Mexico

Follow this and additional works at: https://digitalcommons.chapman.edu/esi_pubs

Part of the Biological and Physical Anthropology Commons, Economic Theory Commons, Ethnic Studies Commons, Latin American Studies Commons, Other Anthropology Commons, Other Economics Commons, and the Social and Cultural Anthropology Commons

\section{Recommended Citation}

Stieglitz, J., Gurven, M., Kaplan, H., \& Hooper, P. L. (2013). Household Task Delegation among High-Fertility Forager-Horticulturalists of Lowland Bolivia. Current Anthropology, 54(2), 232-241. https://doi.org/ $10.1086 / 669708$

This Article is brought to you for free and open access by the Economic Science Institute at Chapman University Digital Commons. It has been accepted for inclusion in ESI Publications by an authorized administrator of Chapman University Digital Commons. For more information, please contact laughtin@chapman.edu. 


\section{Household Task Delegation among High- Fertility Forager-Horticulturalists of Lowland Bolivia}

\author{
Jonathan Stieglitz, Michael Gurven, Hillard Kaplan, and \\ Paul L. Hooper
}

Department of Anthropology, MSC01-1040, University of New Mexico, Albuquerque, New Mexico 87131, U.S.A. (j0nathan@unm.edu)/Integrative Anthropological Sciences, Department of Anthropology, University of California, Santa Barbara, Santa Barbara, California 93106, U.S.A. (Gurven)/Department of Anthropology, University of New Mexico, Albuquerque, New Mexico 87131, U.S.A. (Kaplan and Hooper). This paper was submitted 20 IV 12, accepted 11 II 12, and electronically published 21 II 13.

Human kin cooperation is universal, leading researchers to label humans as "cooperative breeders." Despite widespread interest in human cooperation, there has been no systematic study of how household economic decision making occurs. We document age and sex profiles of task delegation by parents to children ages 4-18 among Bolivian forager-horticulturalists. We test for sex differences in the probability of delegation and examine whether tasks are more likely delegated as household labor demand increases. We also test whether food acquisition tasks are more likely delegated to higher producers. We find mixed support for the prediction that girls are more likely delegated domestic and alloparenting tasks than boys ( $n=173$ children). Both sexes are more likely delegated tasks during rice harvest months; number of coresident young children is also associated with greater probability of delegated allocare, although the effect retains significance for girls only. For both sexes, father absence is associated with greater probability of delegation, particularly for food acquisition tasks. Children delegated rice harvesting achieve $45 \%$ higher mean daily caloric returns from harvesting than children not delegated harvesting. Our results therefore suggest that delegation increases household economic efficiency. We find mixed support for the hypothesis that delegation prepares children for sex-specific adult roles.

Train a child in the way he should go; He will not swerve from it even in old age. (Proverbs 22:6)

\section{Introduction}

Biological models of "cooperative breeding” emphasize ecological constraints on dispersal as a principal motivator of

(C) 2013 by The Wenner-Gren Foundation for Anthropological Research. All rights reserved. 0011-3204/2013/5402-0007\$10.00. DOI: 10.1086/ 669708 helping by reproductively capable, economically self-sufficient offspring (Emlen 1984, 1995). "Helping at the nest" often results from lack of quality territories, mating opportunities, or elevated risks of mortality upon dispersal; offspring delay dispersal because fitness gains of helping parents outweigh costs of forgone reproduction for offspring. Observations of widespread kin cooperation in humans have led researchers to view humans as cooperative breeders with pooled energy budgets (Hill, Barton, and Hurtado 2009; Hrdy 2005; Kramer 2005). Human life histories and patterns of residence and intergenerational cooperation deviate markedly from cooperative breeding avian and mammalian species; existing ecological constraints models thus do not fully explain human cooperative breeding patterns. Yet to date, there has been no systematic study of how household economic decision making occurs. Who decides which tasks to accomplish on a daily basis? To what extent are tasks coordinated to maximize household production? Cooperative breeding models highlight the positive effects of offspring helpers on parental fitness but do not specify which tasks offspring might perform or which ecological, household, and individual characteristics might increase the value of help.

Task delegation, or a verbal request by one individual of another to perform allocare, ${ }^{1}$ is an important medium of learning for children. In subsistence economies, formal instruction is rare as children primarily learn from observation, imitation, and on-the-job training (Lancy and Grove 2010; Tucker and Young 2005). Task delegation represents an alternative to formal instruction where adults facilitate children's learning through on-the-job training. If tasks are delegated to more competent children, delegation can maximize household economic efficiency. While certain tasks simultaneously facilitate children's learning and improve the household economy, current versus future productivity trade-offs may be evident for other tasks. Delegation may also reduce children's leisure time or schooling and thus involves negotiating autonomy. Cultural norms regarding expectations about children's work effort can also be gleaned by documenting patterns of delegation.

Here we examine age and sex profiles of delegation to children ages 4-18 among Tsimane forager-horticulturalists of Bolivia. Tsimane reside in semipermanent villages of extended family household clusters. As a natural fertility population (total fertility rate $=9$ ), households are composed of multiple weaned offspring who provide allocare from an early age. Women's involvement in horticulture entails traveling to distant gardens, sometimes with a nursing infant, and younger weaned offspring may be left at home with older offspring caretakers.

The paper has four objectives. The first is to document

1. For brevity we use the term "allocare" as a substitute for "allomaternal assistance" or "helping at the nest." Allocare is broadly defined as any domestic labor, child care, or food acquisition. "Alloparenting" is more narrowly defined as child care (active or passive) provided by an individual other than a genetic parent. 
normative ages of task completion, with and without delegation, by activity and sex. The second is to examine the prevalence of delegation by sex and test whether girls are more likely delegated tasks than boys (particularly domestic and alloparenting tasks). The third objective is to test whether tasks are more likely delegated as household labor demand increases, using three proxies: rice harvest season (DecemberApril), number of coresident young children $(<$ age 4$)$, and father absence. A fourth objective is to test whether delegation of food acquisition tasks is positively associated with children's daily caloric return rates and time allocation to food acquisition.

\section{Human Life Histories and Parent-Offspring Labor Substitution}

Unlike other cooperative breeders, human offspring remain energetically dependent on parents long after weaning and provide allocare long before sexual maturity. Children may continue providing allocare after forming families of their own. Hill et al. (2011) suggest that the combination of dispersal and bisexual philopatry among human foragers is a residential arrangement not observed among any vertebrate, resulting in preferential interactions with nuclear kin well beyond the juvenile period.

Altriciality of human infants lowers a mother's rate of energy production and time allocation to production (Hames 1988; Hurtado et al. 1992). Even in subsistence economies like the Hadza where adult women's caloric return rates exceed returns of adult men, men's production exceeds women's production in families with young offspring (Marlowe 2003). Offspring do not produce more food than they consume until their mid to late teens (Hooper 2011; Kaplan 1994; Kramer 2005). Despite this high level of offspring dependency, women have shorter interbirth intervals than expected for primates of our size, higher fertility, and higher rates of offspring survivorship (Kaplan et al. 2000).

Although children cannot fully subsidize their own energetic requirements, parents could not maintain high fertility rates without children's labor (Kramer 2005; Lee and Kramer 2002). Older children are the most common alloparents in traditional societies (Weisner et al. 1977), and labor substitution between parents and offspring is a fundamental feature of the household division of labor. If tasks exist that both child and parent can perform equally well, we should expect a parent to substitute a child's labor for his or her own, thereby freeing the parent to perform tasks that the child cannot because of insufficient skill or strength (Bock 2002a, 2002b). Ultimately, this assistance reduces daily energetic costs to parents of reproduction.

Time allocation studies show clear patterns of parent-offspring labor substitution, although the type of labor and participants recruited vary cross-culturally. Nursing Toba women with coresident female helpers (ages 7-15) spend less time in domestic work than women without helpers (Bove, Valeggia, and Ellison 2002). In rural Trinidad, mothers of young chil- dren ( $\leq$ age 4$)$ with female helpers ( $\geq$ age 10) spend less time in child care than mothers without helpers (Flinn 1989). While greater time allocation to subsistence work entails less time for child care (Hames 1988), Aka mothers' time allocation to work is not correlated with the amount of care received by infants (Meehan 2009). Tsimane fathers' time allocation to caring for young children $(<$ age 4$)$ is inversely related to the proportional representation of coresident older daughters ( $\geq$ age 7; Winking et al. 2009). While Efe children of both sexes commonly alloparent, older sisters and brothers spend only 11 and 6 minutes per day, respectively, in "active care" (i.e., requiring prolonged caregiver attention), which represents $15 \%$ and $8 \%$, respectively, of a mother's allocation (Ivey 2000). Alloparenting might therefore be biased toward weaned dependents, thus freeing a mother to engage in other tasks. Time allocation to infant care is less variable for mothers than for other caregivers cross-culturally (Kramer 2005), indicating that nursing is not an easily substitutable form of parental investment. Indeed, presence of alloparents does not affect nursing frequency or duration (Bove, Valeggia, and Ellison 2002). Even when infant alloparenting occurs, quality of care might not be compromised relative to maternal care (Borgerhoff Mulder and Milton 1985).

Demographic studies examining effects of children's allocare on parental reproductive success are consistent with the time allocation studies reviewed above. Presence of offspring helpers ( $\geq$ age 5) of either sex increases Aymara women's fertility and offspring survivorship, particularly through domestic, alloparenting, pastoral, and agricultural labor inputs (Crognier, Villena, and Vargas 2002). While Sear, Mace, and McGregor (2003) find no effect of the presence of offspring helpers on rural Gambian women's birth rates, Gambian children ages $2-5$ with at least one sister $10+$ years their senior experience higher survival rates than children without elder sisters (Sear et al. 2002). If mothers are reducing investment in weanlings to prepare for subsequent births, then this period of time can be dangerous for weanlings, thus increasing the value of older children's allocare.

Given the positive effects of children's allocare on parental fitness, selection likely favored a parental psychology sensitive to cues of household need and children's abilities. Parents should thus be motivated to modify children's time use, as indifferent parents would not redistribute energetic costs of reproduction as efficiently. Under some circumstances, task delegation might result in parent-offspring conflict if benefits of children's immediate production outweigh costs of children's forgone skill or social capital development for parents but not for children (Bock 2002a; Trivers 1974). But when interests of parent and child fully coincide, task delegation promotes cooperation when willing but inexperienced children lack a sense of immediate production requirements.

\section{Ethnographic Research on Task Delegation}

Previous research highlights effects of subsistence economy, household labor demand, and offspring gender on the extent 
of compliance pressures on children. Early observations of forager children suggested that expectations of high work effort were uncommon and that much of children's work is self-initiated, self-guided, and self-taught. In contrast, children are more likely assigned tasks in agricultural and pastoral societies (see references in Gurven and Kaplan 2006 and Hames and Draper 2004). Maternal subsistence involvement, particularly in horticulture or agriculture, may favor greater manipulation of children's time to minimize interference with the mother's work and promote labor substitution for safe, low-strength, and low-skill tasks that children can perform efficiently (Barry, Child, and Bacon 1959; Brown 1973; Draper and Cashdan 1988; Gurven and Kaplan 2006; Munroe and Munroe 1977; Whiting and Whiting 1975). In contrast, opportunities to accomplish such tasks may be limited among nomadic foragers given the dangers associated with mobility and relative paucity of easy-to-accomplish tasks. Household labor demand may interact with subsistence economy to increase compliance pressures on children, particularly with presence of an infant, fewer sibling substitute laborers, or father absence (Bock 2002a, 2002b; Ember 1973).

Barry, Bacon, and Child (1957) argue that pressure toward responsibility is stronger for girls than for boys cross-culturally. Girls may be delegated more tasks than boys, in part, because girls maintain closer proximity to the home and adults. This "opportunistic delegation" hypothesis is an alternative to the "systematic delegation" hypothesis, which states that parents delegate tasks to prepare children for adult roles (Draper 1975; Draper and Cashdan 1988; Erchak 1980; Whiting and Whiting 1975). The latter hypothesis implies that sex differences in delegation reflect the sexual division of adult labor. According to this hypothesis, girls may be delegated more tasks than boys given the high demand for domestic labor and alloparenting; in natural fertility subsistence economies, both of these tasks figure prominently in adult women's but not men's time allocation profiles.

\section{Predictions}

We test the following predictions: (1) girls are more likely delegated domestic and alloparenting tasks than boys, (2) tasks are more likely delegated during rice harvest months for both sexes, (3) the probability of delegation increases with the number of coresident young children (< age 4) for both sexes, (4) the probability of delegation increases in fatherabsent households for both sexes, and (5) delegation of food acquisition tasks is positively associated with children's daily caloric return rate and time allocation to those tasks.

\section{Methods}

\section{Study Population}

Tsimane reside in the rainforests and savannas of lowland Bolivia. Their diet consists largely of meat, fish, rice, plantains, and fruit. Tsimane fish with hooks, bow and arrow, and nets.
Rifles or shotguns are used on most hunts, although hunters of all ages continue to use bow and arrow. Other important cultigens include corn and sweet manioc, both of which are processed to make beer (chicha). All cultigens except rice are harvested throughout the year. Store-bought items represent a small portion of the diet and include sugar, salt, pasta, charqui (dried meat), and cooking oil. Other store-bought items include kitchen utensils, fishhooks, bullets, machetes, medicine, and clothing. Items are purchased with cash obtained through men's sporadic itinerant wage labor with loggers, ranchers, or river merchants. Most villages are located near rivers or oxbow lakes and lack electricity or running water. Schools exist in most villages, although attendance is sporadic.

Sex roles are well defined: women provide child care, process and prepare food, and make chicha. Men hunt, chop trees, and occasionally engage in wage labor. Both sexes fish, collect fruit and honey, fetch wood and water, and work in horticultural fields. In the present sample, mothers delegated the majority of tasks (78\%). Fathers delegated 7\% of tasks, older sisters $5 \%$, and grandparents $5 \%$.

\section{Data Collection}

Task delegation data were collected by one of the authors (Stieglitz) and two Tsimane research assistants from 2006 to 2008 in four villages. Interviews included an exhaustive list of children's tasks generated from systematic behavioral observations. Mothers were asked whether a focal child performed each task the previous day, the number of times the task was performed, and the duration of each task. For each completed task we asked whether it was delegated (jutete) or performed voluntarily (cui'si ya dyijyedye'). If a task was delegated, we asked whether the child complied immediately (se'vaqui cavintum) or resisted (jam må’je' se'vaqui). This improved participant recall and helped resolve inconsistencies. We also recorded the whereabouts of male household heads; fathers were considered absent if they were not in the village during daylight hours of the previous day. Families with at least one child age 4-18 were eligible to participate, and no families refused participation. Families were sampled multiple times throughout the year to ensure a representative sample of children's work effort. Nearly half of all children (45\%) were sampled during both harvest and nonharvest months; $46 \%$ of all tasks were performed during harvest months (December-April). To increase sample size, we sampled multiple children in $62 \%$ of families. The sample includes 173 children (91 male, 82 female) from 69 families. On average, children were sampled 3.4 days (median $=4$, minimum $=1$, maximum $=6$ ). Mean \pm SD age of child is $10 \pm 4$.

Interview data on food production and time allocation were simultaneously collected by Tsimane research assistants roughly twice per week on a subset of families (mean \pm SD sample days for children $=96 \pm 40)$. Number of hours spent in subsistence macro categories (e.g., horticulture, fishing) was recorded for each producer in the family during the pre- 

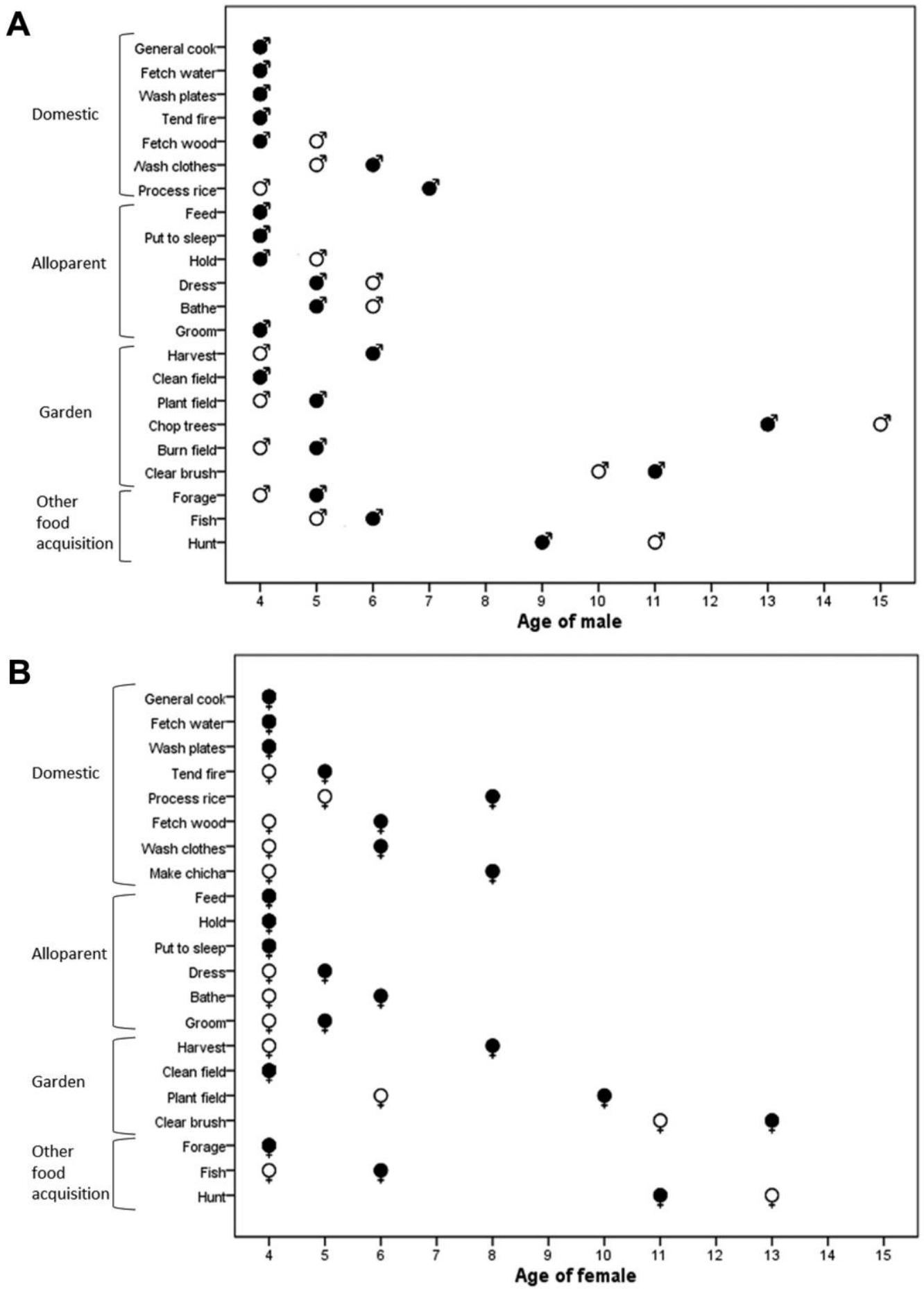

Figure 1. Minimum ages of task completion with and without delegation (shaded and open symbols, respectively) for $(A)$ boys $(n=91)$ and $(B)$ girls $(n=82)$. For tasks showing one symbol, minimum ages of completion with and without delegation are identical. Tasks are presented in descending order of frequency per macro category for each sex. Any task not delegated and completed voluntarily by at least one individual is omitted. 
vious two days. We inquired about quantities produced for each activity per person per day. For details regarding estimation of age-specific production, see Hooper (2011).

Demographic interviews used to assign ages and assess kinship were conducted by Stieglitz, Gurven, and a senior graduate student from 2003 to 2007 (see Gurven, Kaplan, and Supa 2007 for details). These data were updated during subsequent censuses.

\section{Data Analysis}

We use mixed effects logistic regression to model the probability of delegation while controlling for repeated measures at family and individual levels. We include family identification (ID) and person ID as random effects. ${ }^{2}$ Results are presented separately for boys and girls, as either odds ratios (OR) or predicted probabilities. We use multiple linear regression to model the associations between delegation, daily caloric return rates, and time allocation; for these analyses we use the combined sample of boys and girls and control for sex. ${ }^{3}$

\section{Results}

\section{Normative Ages of Task Completion}

For both sexes, common domestic tasks (cooking, fetching water, washing plates) are delegated and completed voluntarily at a young age (fig. $1 A, 1 B$ ). Domestic tasks performed less frequently (washing clothes, processing rice, making chicha) are delegated at older ages, although voluntary participation occurs earlier. Common alloparenting tasks (feeding, encouraging infants to sleep) are also delegated and completed voluntarily at a young age for both sexes. For some alloparenting tasks (holding, dressing, bathing), young boys voluntarily alloparent only after such tasks are delegated; young girls, in contrast, voluntarily alloparent regardless of when delegation begins. Although garden tasks are performed less frequently than domestic tasks or alloparenting, young boys and girls voluntarily perform common garden tasks (harvesting, cleaning fields) regardless of when delegation begins. Garden tasks performed less frequently (chopping trees, clearing brush) are delegated at older ages. For both sexes, fishing is delegated later than foraging but earlier than hunting. In most cases, delegation of hunting encourages children (mostly boys) to accompany fathers in nonproductive "apprenticeship" roles, although children of both sexes may also assist in carrying items and processing game.

Probability of delegation linearly declines with age for boys $(\mathrm{OR}=0.93 /$ year; $P=.002)$ but not for girls (table 1$)$. For boys, significant age-related decline in the probability of delegation is evident for five of seven domestic and four of six

2. Individuals residing in the same household share a family ID.

3. The pooled sample is used to increase sample size and because we are not concerned with sex differences in production for the present analysis.
Table 1. Age at peak probability of delegation by sex

\begin{tabular}{|c|c|c|}
\hline \multirow[b]{2}{*}{$\begin{array}{l}\text { Macro category and task } \\
\text { ( } n \text { tasks for boys, girls) }\end{array}$} & \multicolumn{2}{|c|}{$\begin{array}{l}\text { Age at peak probability of } \\
\text { delegation }^{\mathrm{a}}\end{array}$} \\
\hline & $\begin{array}{c}\text { Boys } \\
(n=91)\end{array}$ & $\begin{array}{c}\text { Girls } \\
(n=82)\end{array}$ \\
\hline All tasks $(2,911,4,241)$ & $4^{* * *}$ & $9^{*}$ \\
\hline Domestic $(1,615,2,379)$ & $4^{* * *}$ & $10^{* * *}$ \\
\hline General cook $(649,721)$ & $4^{* *}$ & NS \\
\hline Fetch water $(383,566)$ & $9^{* *}$ & $4^{* * *}$ \\
\hline Wash plates $(238,422)$ & $4^{* *}$ & $10^{* *}$ \\
\hline Tend fire $(115,188)$ & $4^{* *}$ & NS \\
\hline Fetch wood $(95,162)$ & $4^{* *}$ & $10^{*}$ \\
\hline Wash clothes $(69,116)$ & $6^{* * *}$ & $6^{* *}$ \\
\hline Process rice $(61,178)$ & NS & $8^{*}$ \\
\hline Make chicha $(5,26)$ & $\mathrm{NA}^{\mathrm{b}}$ & $17^{\star}$ \\
\hline Alloparent $(944,1591)$ & $4^{* * *}$ & $4^{* * *}$ \\
\hline Feed $(317,466)$ & $4^{*}$ & NS \\
\hline Put to sleep $(180,304)$ & NS & $4^{* * *}$ \\
\hline Hold $(135,340)$ & $4^{* * *}$ & $4^{* * *}$ \\
\hline Dress $(132,190)$ & $5^{*}$ & NS \\
\hline Bathe $(112,164)$ & $5^{* *}$ & NS \\
\hline Groom $(68,127)$ & NS & NS \\
\hline Food acquisition $(352,271)$ & $12^{\star * *}$ & $15^{*}$ \\
\hline Garden $(185,152)$ & $11^{\star * *}$ & $15^{*}$ \\
\hline Harvest $(82,102)$ & NS & $13^{* *}$ \\
\hline Clean field $(64,31)$ & $11^{\star *}$ & NS \\
\hline Plant field $(21,6)$ & $\mathrm{NA}^{\mathrm{b}}$ & $\mathrm{NA}^{\mathrm{b}}$ \\
\hline Chop trees $(8,4)$ & $\mathrm{NA}^{\mathrm{b}}$ & $\mathrm{NA}^{\mathrm{b}}$ \\
\hline Burn field $(6,4)$ & $\mathrm{NA}^{\mathrm{b}}$ & $\mathrm{NA}^{\mathrm{b}}$ \\
\hline Clear brush $(4,5)$ & $\mathrm{NA}^{\mathrm{b}}$ & $\mathrm{NA}^{\mathrm{b}}$ \\
\hline Forage $(76,81)$ & NS & NS \\
\hline Fish $(76,34)$ & $10^{*}$ & NS \\
\hline Hunt $(15,4)$ & $\mathrm{NA}^{\mathrm{b}}$ & $\mathrm{NA}^{\mathrm{b}}$ \\
\hline \multicolumn{3}{|c|}{$\begin{array}{l}{ }^{*} P \leq .10 . \\
\text { ** } P \leq .05 . \\
* * * \quad P \leq .01 . \\
\text { a In a mixed effects logistic regression controlling for season (harvest } \\
\text { vs. nonharvest) and repeated measures at family and individual levels. } \\
\text { b Validity of model fit is uncertain because of the small number of tasks } \\
\text { or delegated tasks. }\end{array}$} \\
\hline
\end{tabular}

alloparenting tasks (for feeding and dressing siblings the effect of age approaches significance). Peak probability of delegation for fetching water, cleaning fields, and fishing for boys occurs at ages 9,11 , and 10, respectively. For girls, age-related decline in the probability of delegation is evident for three of eight domestic and two of six alloparenting tasks. Peak probability of delegation for washing plates and fetching wood occurs at age 10 , while harvesting is most likely delegated at age 13 . Probability of delegation for making chicha marginally increases with age.

Prevalence of Delegation by Sex of Child and Effect of Sex on the Probability of Delegation

Nearly all individuals are delegated tasks (table 2). Girls are more likely than boys to be delegated and to voluntarily complete domestic tasks. Girls are more likely delegated cooking $(\mathrm{OR}=2.17)$, washing plates $(\mathrm{OR}=2.24)$, and tending fires 
Table 2. Percentage of children delegated a task, percentage of tasks that were delegated, and effect of sex on the probability of delegation

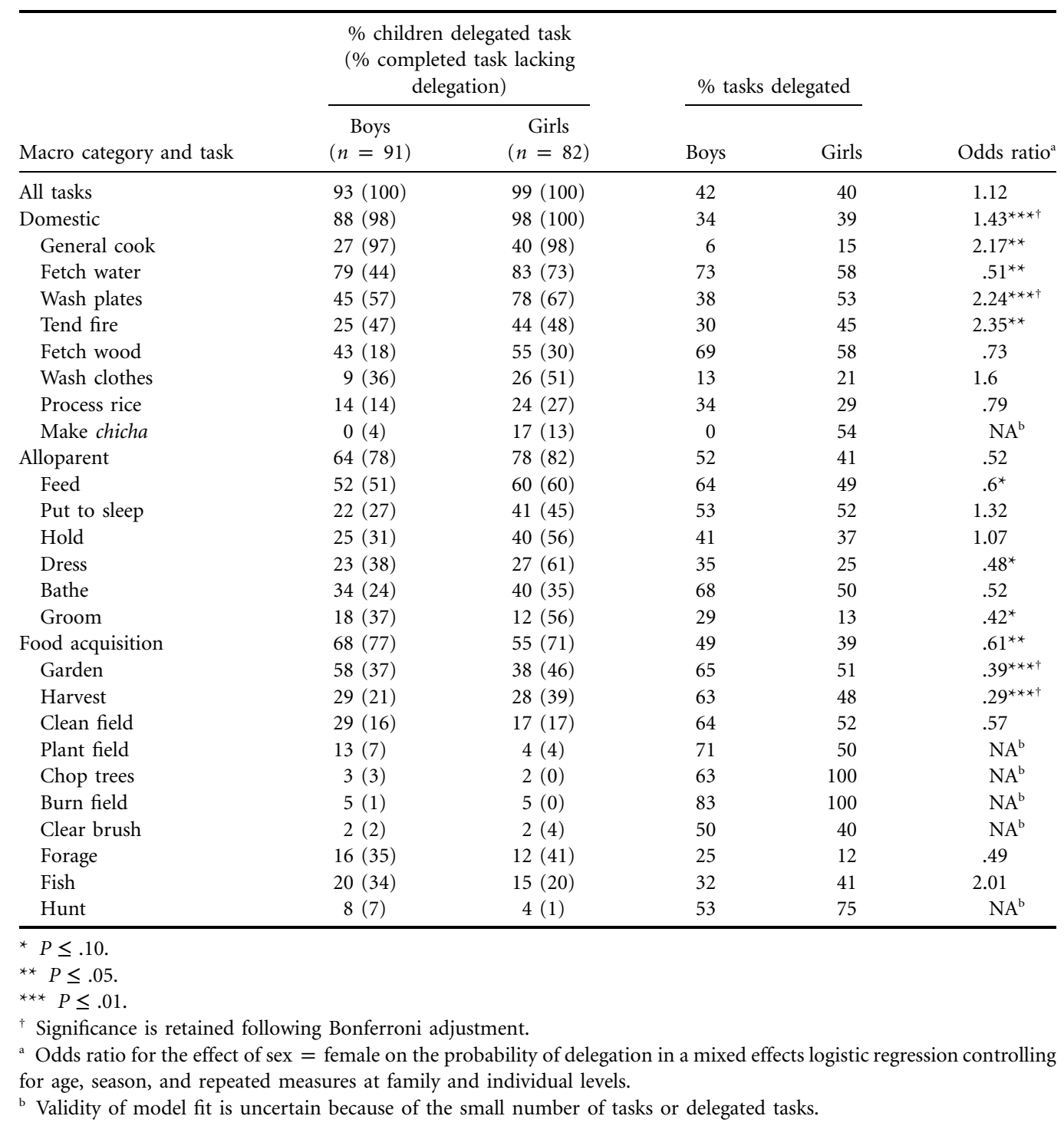

$(\mathrm{OR}=2.35)$ than boys; odds of delegation for fetching water, however, are roughly $50 \%$ lower for girls $(\mathrm{OR}=0.51)$. No sex differences emerged in the probability of delegation for domestic tasks performed less frequently. Proportionally more girls than boys are delegated alloparenting tasks (excluding the least common alloparenting task for both sexes [grooming]). Girls are also more likely to voluntarily alloparent across tasks. However, over $60 \%$ of boys are delegated alloparenting and boys are marginally more likely delegated feeding, dressing, and grooming siblings than girls. When the two least common garden tasks (burning and clearing) are excluded, boys are more likely than girls to be delegated food acquisition tasks. Girls are more likely than boys to voluntarily harvest; odds of delegation for harvesting are over 70\% lower for girls.

\section{Are Tasks More Likely Delegated during Rice Harvest} Months?

For boys, common domestic tasks are more likely delegated during harvest months including cooking $(\mathrm{OR}=1.8, P=$ .077 , controlling for age) and fetching water $(\mathrm{OR}=2.5$, $P=.026$ ). In addition, odds of delegation for harvesting are nearly eight times greater for boys during harvest months relative to nonharvest months $(\mathrm{OR}=7.7, P=.01)$. Alloparenting is not more likely delegated to boys during harvest months.

For girls, odds of delegation for processing rice are 3.1 times greater during harvest months relative to nonharvest months $(P=.073)$. In addition, girls are more likely delegated four of six alloparenting tasks during harvest months including 
feeding $(\mathrm{OR}=2.46, P=.027)$, encouraging infants to sleep $(\mathrm{OR}=4.55, P=.01)$, bathing $(\mathrm{OR}=7.19, P=.003)$, and grooming $(\mathrm{OR}=3.75, P=.10)$. Harvesting is not more likely delegated to girls during harvest months.

\section{Are Tasks More Likely Delegated with More Coresident Young Children?}

For both sexes, number of young children (< age 4$)$ is associated with greater probability of delegation for five domestic tasks (table 3), although no effects retain significance after accounting for the number of tests. For both sexes, number of young children is associated with significantly greater probability of delegation for two alloparenting tasks, although the effects retain significance for girls only (fig. 2). While for boys number of young children has no effect on the probability of delegation for any food acquisition task, girls are more likely delegated harvesting $(\mathrm{OR}=3.75 /$ young child, $P=.022$, controlling for age, season, number of children $\geq$ age 4 , and father absence).

\section{Are Tasks More Likely Delegated in Father-Absent}

\section{Households?}

For boys, father absence is associated with greater odds of delegation for six of seven domestic tasks, although not one effect is significant at $P \leq .1$. Father absence is associated with significantly or marginally greater odds of delegation for four of six alloparenting tasks including feeding $(\mathrm{OR}=2.74$, $P=.016)$, bathing $(\mathrm{OR}=4.01, P=.1)$, dressing $(\mathrm{OR}=$ 3.25, $P=.087)$, and holding $(\mathrm{OR}=4.78, P=.077)$. Father

Table 3. Effect of number of coresident young children $(<$ age 4$)$ on the probability of delegation

\begin{tabular}{lcc}
\hline Macro category and task & Boys & Girls \\
\hline Domestic & $1.27^{*}$ & 1.26 \\
General cook & 1.18 & $1.90^{* *}$ \\
Fetch water & .76 & 1.07 \\
Wash plates & 1.53 & 1.25 \\
Tend fire & .67 & .67 \\
Fetch wood & 1.03 & .60 \\
Wash clothes & 1.17 & 1.14 \\
Process rice & $5.88^{*}$ & .72 \\
Make chicha & $\mathrm{NA}^{\mathrm{a}}$ & 3.52 \\
Alloparent & $1.66^{*}$ & $2.12^{* * * \dagger}$ \\
Feed & $2.6^{* *}$ & 1.43 \\
Put to sleep & $6.16^{* *}$ & $3.74^{* * * \dagger}$ \\
Hold & .38 & $5.28^{* * * \dagger}$ \\
Dress & 1.69 & 1.73 \\
Bathe & .76 & 1.18 \\
Groom & .78 & .60 \\
\hline
\end{tabular}

Note. Odds ratios are adjusted for age, season, number of children $\geq$ age 4 , father absence, and repeated measures at family and individual levels.

$\star P \leq .10$.

${ }^{\star *} P \leq .05$.

*** $P \leq .01$

${ }^{\dagger}$ Significance is retained following Bonferroni adjustment.

a Task not delegated.

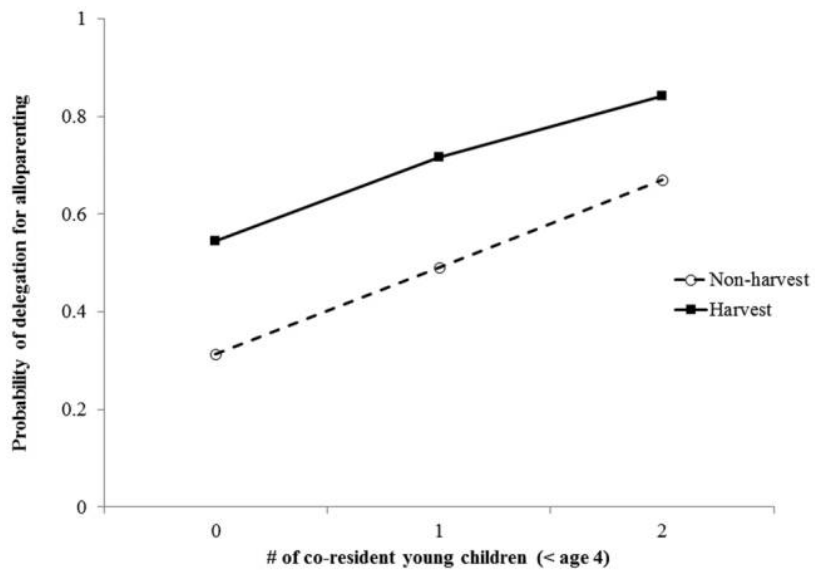

Figure 2. Probability of delegated alloparenting for girls by number of coresident young children and season. Age and number of older children ( $\geq$ age 4$)$ are set to sample means.

absence is also associated with greater probability of delegated fishing $(\mathrm{OR}=8.04, P=.01$; fig. $3 A$ ).

For girls, father absence is associated with significantly or marginally greater odds of delegation for fetching wood (OR $=3.90, P=.044)$ and washing plates $(\mathrm{OR}=1.81, P=$ $.064)$. While father absence is also associated with greater odds of delegation for five of six alloparenting tasks, not one effect is significant at $P \leq .1$. Father absence is associated with greater probability of delegated harvesting $(\mathrm{OR}=10.23, P=.001$; fig. $3 B$ ).

\section{Are Food Acquisition Tasks More Likely Delegated to Higher Producers?}

Children delegated harvesting of rice and other cultigens achieve significantly higher daily caloric returns from those activities than children not delegated such tasks after controlling for age, sex, and body mass index (BMI) as a proxy for strength (table 4). The positive association between delegation and return rate is slightly stronger for rice than for other cultigens: children delegated harvesting of rice and other cultigens achieve $45 \%$ and $43 \%$ higher mean daily caloric returns from those activities than children not delegated such tasks. In addition, children delegated harvesting of rice and other cultigens allocate $52 \%$ and $38 \%$ more time to those tasks, on average, than children not delegated harvesting ( $P=.07$ for rice; $P=.1$ for other cultigens; fig. 4 ). For fishing, there is no association between delegation and either return rate or time allocation.

\section{Discussion}

For both sexes, common domestic and alloparenting tasks are delegated at young ages, particularly lower-skill and lowerstrength tasks that young children can perform efficiently (cf. Gurven and Kaplan 2006). Higher-skill and higher-strength tasks involving greater endurance and risk such as hunting, 

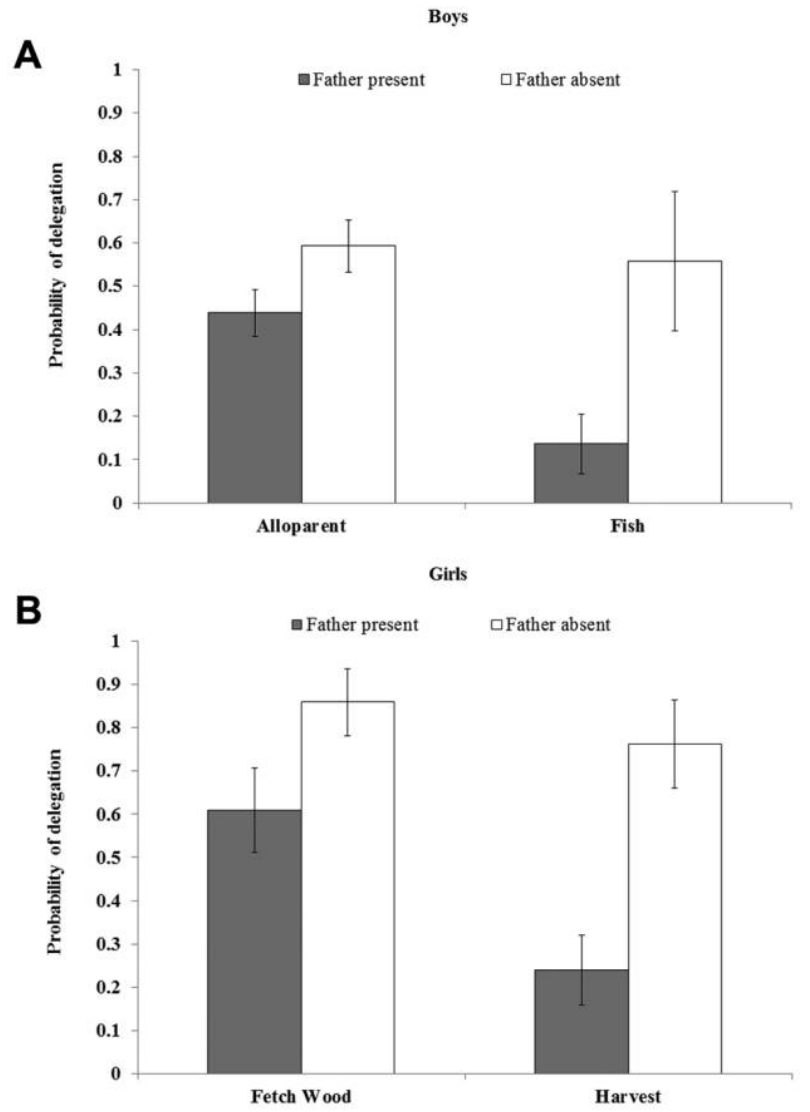

Figure 3. Probability of delegating selected tasks by father absence for $(A)$ boys and $(B)$ girls. Age, season, and number of coresident young and older children are set to sample means. Garden area does not affect the probability of delegated harvesting for girls and is omitted from the model.

clearing fields, and chopping trees are delegated at older ages. While both sexes voluntarily increase work effort with age, age-related decline in the probability of delegation is more strongly evident for boys than for girls (table 1). With age, boys may spend less time under parental supervision than girls and may be afforded more leisure time (Barry, Bacon, and Child 1957; Draper 1975). The extent to which children's voluntary maintenance of proximity to parents influences the number and types of tasks delegated to children remains unexplored.

The prediction that girls are more likely delegated domestic and alloparenting tasks than boys received mixed support. Girls are more likely delegated domestic tasks (table 2), which is consistent with previous research (Barry, Bacon, and Child 1957; Draper 1975; Draper and Cashdan 1988; Erchak 1980; Whiting and Whiting 1975). However, we find no evidence that girls are more likely delegated alloparenting. Rather, the opposite trend emerged, which might partially reflect the fact that girls are more likely than boys to voluntarily alloparent.

The prediction that tasks are more likely delegated during rice harvest months for both sexes received strong support. During harvest months, boys are more likely delegated common domestic tasks and harvesting. Girls are more likely delegated rice processing and alloparenting. This pattern of parent-offspring labor substitution in which boys and girls are delegated distinct tasks increases parents' efficiency by freeing them to engage in other tasks that children cannot perform because of insufficient skill or strength. Indeed, number of children may be positively associated with parents' return rates and time allocation to work (Hurtado et al. 1992; Kaplan 1994). The eightfold increase in the probability of delegated harvesting for boys during harvest months indicates how parents recruit children to subsidize their own growth when seasonal changes favor children's participation in energetic production and costs of spoilage are high in resource-limited settings.

The number of coresident young children is associated with a significantly greater probability of delegated alloparenting for girls (table 3). In addition, odds of delegated harvesting for girls increase fourfold with each additional young child, further indicating how parents utilize children's energetic production to reduce energetic costs to parents as labor demand increases. After accounting for the number of tests, we find no evidence that the number of young children is associated with a greater probability of delegation of any task for boys.

Table 4. Association between children's return rates from harvesting or fishing and whether these tasks were delegated, controlling for age, sex, BMI, family ID, and community ID

\begin{tabular}{|c|c|c|c|c|c|c|}
\hline \multirow[b]{4}{*}{ Parameter } & \multicolumn{6}{|c|}{ Daily caloric returns } \\
\hline & \multicolumn{4}{|c|}{ Harvesting } & & \\
\hline & \multicolumn{2}{|c|}{ Rice } & \multicolumn{2}{|c|}{ Other cultigens } & \multicolumn{2}{|c|}{ Fishing } \\
\hline & B & $\mathrm{P}$ & B & $\mathrm{P}$ & B & $\mathrm{P}$ \\
\hline Delegated (baseline: not delegated) & 362.23 & .05 & 101.54 & .07 & -1.24 & .97 \\
\hline Age & 84.17 & .03 & 30.60 & .01 & 7.55 & .28 \\
\hline Sex $=$ male & 106.72 & .54 & -130.56 & .01 & 81.07 & .02 \\
\hline BMI & 33.64 & .44 & 13.05 & .34 & .72 & .93 \\
\hline Adjusted $R^{2}$ & \multicolumn{2}{|c|}{.26} & \multicolumn{2}{|c|}{.29} & \multicolumn{2}{|c|}{.05} \\
\hline$N$ & \multicolumn{2}{|c|}{107} & \multicolumn{2}{|c|}{109} & \multicolumn{2}{|c|}{95} \\
\hline
\end{tabular}

Note. Intercept, family, and community controls are not shown. 

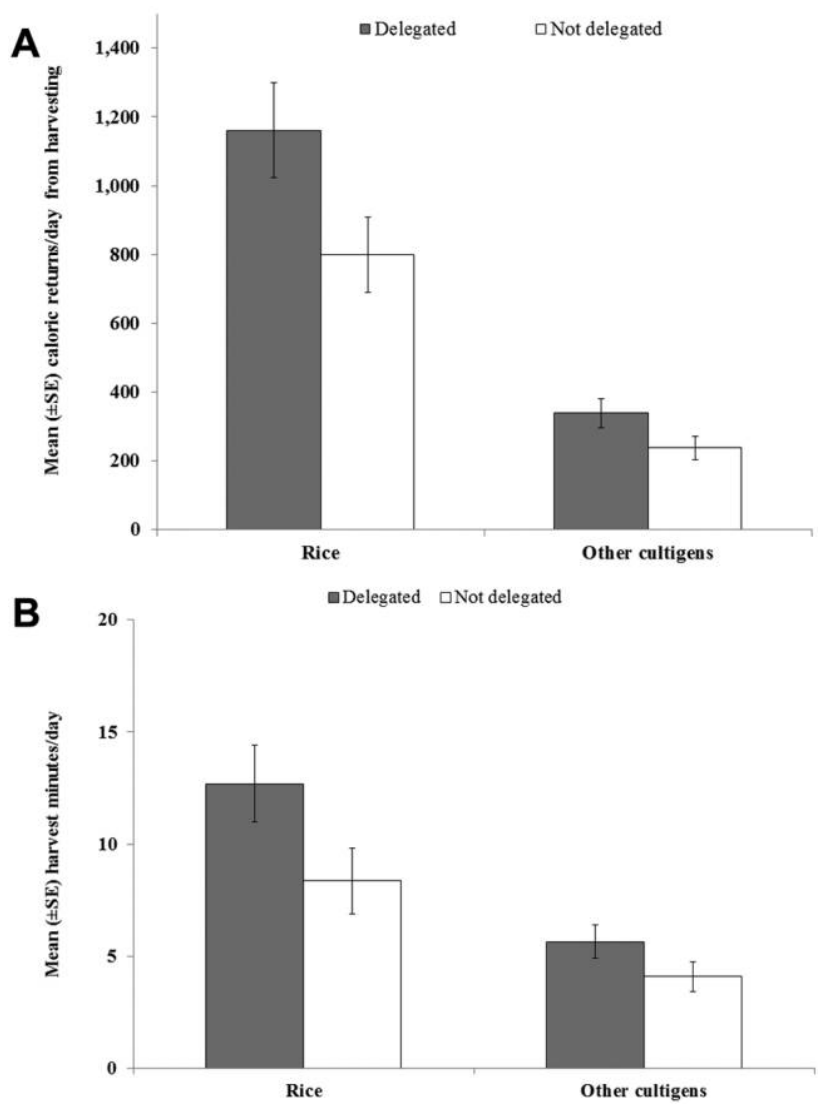

Figure 4. Comparison of $(A)$ daily caloric return rates for harvesting and $(B)$ time allocation to harvesting by whether children were delegated harvesting. Age, sex, and BMI are set to sample means.

For both sexes, the positive association between father absence and the probability of delegation is strongest for food acquisition tasks (fig. 3A, 3B). Children's energetic production partially compensates for the short-term energetic deficit associated with male absenteeism. The greater probability of delegated fishing to boys and harvesting to girls in fatherabsent households increases macronutrient diversity and facilitates training for adult roles in which males specialize in acquiring protein and females specialize in acquiring carbohydrates. At the same time, the greater probability of delegated alloparenting to boys in father-absent households suggests that when labor demand increases, children may be opportunistically recruited as helpers without consideration of adult roles (cf. Ember 1973).

Children delegated harvesting achieve higher harvesting returns and allocate more time to harvesting than children not delegated harvesting. This suggests that parents have knowledge of children's horticultural abilities and use this knowledge to modify children's behavior in a way that increases household production. The positive association between delegation of harvesting and harvesting return rate might reflect a history of greater training through delegation. Alternatively, harvesting returns may be independent of delegation, and parents may delegate harvesting to higher producers to increase short-term production rather than facilitate training of already competent children. Another possibility is that children delegated harvesting are more likely delegated other tasks as well, which would diminish the association between delegation and return rate. However, we find no evidence that children delegated harvesting are delegated more tasks relative to children not delegated harvesting controlling for age, sex, number of days sampled, and family ID. Interestingly, we find no association between delegation of fishing and children's fishing return rate or time allocation to fishing. This might suggest that the primary motivation to parents for delegating fishing is to facilitate children's learning and maximize longterm rather than short-term production.

To conclude, delegation of labor to children depends on children's size- and skill-dependent abilities, household labor requirements, and the value of on-the-job training. By coordinating daily tasks, parents efficiently redistribute energetic costs of reproduction. While we find that children are delegated tasks that prepare them for sex-specific adult roles, both sexes are also delegated tasks exhibiting a marked sexual division of labor in adulthood. Furthermore, children independently prepare for adult roles by voluntarily pursuing sexspecific tasks.

\section{Acknowledgments}

We thank the Tsimane for their strong collaboration and hospitality. Bacilio Vie and Miguel Mayer collected a portion of task delegation, production, and time allocation data. Amanda Veile collected a portion of demography data. Funding was provided by the National Science Foundation (BCS-0721237) and the National Institutes of Health/National Institute on Aging (R01AG024119-01, 2P01AG022500-06A1).

\section{References Cited}

Barry, H., III, M. K. Bacon, and I. Child. 1957. A cross-cultural survey of some sex differences in socialization. Journal of Abnormal and Social Psychology 55:327-332.

Barry, H., III, I. Child, and M. K. Bacon. 1959. Relation of child training to subsistence economy. American Anthropologist 61:51-63.

Bock, J. 2002a. Evolutionary demography and intrahousehold time allocation: schooling and children's labor among the Okavango Delta peoples of Botswana. American Journal of Human Biology 14:206-221.

. $2002 b$. Learning, life history, and productivity: children's lives in the Okavango Delta, Botswana. Human Nature 13:161-197.

Borgerhoff Mulder, M., and K. Milton. 1985. Factors affecting infant care in the Kipsigis. Journal of Anthropological Research 41:231-262.

Bove, R., C. Valeggia, and P. Ellison. 2002. Girl helpers and time allocation of nursing women among the Toba of Argentina. Human Nature 13:457472 .

Brown, J. K. 1973. The subsistence activities of women and the socialization of children. Ethos 1(4):413-423.

Crognier, E., M. Villena, and E. Vargas. 2002. Helping patterns and reproductive success in Aymara communities. American Journal of Human Biology 14:372-379. 
Draper, P. 1975. Cultural pressure on sex differences. American Ethnologist 2: 602-616.

Draper, P., and E. Cashdan. 1988. Technological change and child behavior among the !Kung. Ethnology 27:339-365.

Ember, C. R. 1973. Feminine task assignment and the social behavior of boys. Ethos 1(4):424-439.

Emlen, S. 1984. Cooperative breeding in birds and mammals. In Behavioural ecology: an evolutionary approach. J. Krebs and N. Davies, eds. Pp. 305335. Oxford: Oxford University Press.

- 1995. An evolutionary theory of the family. Proceedings of the National Academy of Sciences 92:8092-8099.

Erchak, G. 1980. The acquisition of cultural rules by Kpelle children. Ethos 8:40-48.

Flinn, M. 1989. Household composition and female reproductive strategies in a Trinidadian village. In The sociobiology of sexual and reproductive strategies. A. Rasa, C. Vogel, and E. Voland, eds. Pp. 206-233. London: Chapman $\&$ Hall.

Gurven, M., and H. Kaplan. 2006. Determinants of time allocation across the lifespan: a theoretical model and an application to the Machiguenga and Piro of Peru. Human Nature 17:1-49.

Gurven, M., H. Kaplan, and A. Zelada Supa. 2007. Mortality experience of Tsimane Amerindians of Bolivia: regional variation and temporal trends. American Journal of Human Biology 19:376-398.

Hames, R. 1988. The allocation of parental care among the Ye'kwana. In Human reproductive behavior: a Darwinian perspective. L. Betzig, M. Borgerhoff Mulder, and P. Turke, eds. Pp. 237-254. Cambridge: Cambridge University Press.

Hames, R., and P. Draper. 2004. Women's work, child care, and helpers-atthe-nest in a hunter-gatherer society. Human Nature 15(4):319-341.

Hill, K., M. Barton, and A. M. Hurtado. 2009. The emergence of human uniqueness: characters underlying behavioral modernity. Evolutionary Anthropology 18:187-200.

Hill, K. R., R. S. Walker, M. Božičević, J. Eder, T. Headland, B. Hewlett, A. M. Hurtado, F. Marlowe, P. Wiessner, and B. Wood. 2011. Co-residence patterns in hunter-gatherer societies show unique human social structure. Science 331:1286-1289.

Hooper, P. 2011. The structure of energy production and redistribution among Tsimane' forager-horticulturalists. $\mathrm{PhD}$ dissertation, University of New Mexico.

Hrdy, S. 2005. Comes the child before man: how cooperative breeding and prolonged postweaning dependence shaped human potential. In Hunter gatherer childhoods: evolutionary, developmental, and cultural perspectives. B. Hewlett and M. Lamb, eds. Pp. 65-91. New Brunswick, NJ: Aldine.
Hurtado, A., K. Hill, H. Kaplan, and I. Hurtado. 1992. Trade-offs between female food acquisition and child care among Hiwi and Ache foragers. Human Nature 3:185-216.

Ivey, P. 2000. Cooperative reproduction in Ituri Forest hunter-gatherers: who cares for Efe infants? Current Anthropology 41:856-866.

Kaplan, H. 1994. Evolutionary and wealth flows theories of fertility: empirical tests and new models. Population and Development Review 20:753-791.

Kaplan, H., K. Hill, J. Lancaster, and A. Hurtado. 2000. A theory of human life history evolution: diet, intelligence, and longevity. Evolutionary Anthropology 9:156-185.

Kramer, K. 2005. Children's help and the pace of reproduction: cooperative breeding in humans. Evolutionary Anthropology 14:224-237.

Lancy, D., and A. Grove. 2010. Learning guided by others. In The anthropology of learning in childhood. D. Lancy, S. Gaskins, and J. Bock, eds. Pp. 145179. Lanham, MD: Alta-Mira.

Lee, R., and K. Kramer. 2002. Children's economic roles in the Maya family life cycle: Cain, Caldwell, and Chayanov revisited. Population and Development Review 28:475-499.

Marlowe, F. 2003. A critical period for provisioning by Hadza men. Evolution and Human Behavior 24:217-229.

Meehan, C. 2009. Maternal time allocation in two cooperative childrearing societies. Human Nature 20:375-393.

Munroe, R. L., and R. H. Munroe. 1977. Land, labor, and the child's cognitive performance among the Logoli. American Ethnologist 4:309-320.

Sear, R., R. Mace, and I. McGregor. 2003. The effects of kin on female fertility in rural Gambia. Evolution and Human Behavior 24:25-42.

Sear, R., F. Steele, I. McGregor, and R. Mace. 2002. The effects of kin on child mortality in rural Gambia. Demography 39:43-63.

Trivers, R. 1974. Parent-offspring conflict. American Zoologist 14:249-264.

Tucker, B., and A. Young. 2005. Growing up Mikea: children's time allocation and tuber foraging in southwestern Madagascar. In Hunter-gatherer childhoods: evolutionary, developmental, and cultural perspectives. B. Hewlett and M. Lamb, eds. Pp. 147-171. New Brunswick, NJ: Aldine.

Weisner, T. S., R. Gallimore, M. K. Bacon, H. Barry III, C. Bell, N. Sylvia Caiuby, C. P. Edwards, et al. 1977. My brother's keeper: child and sibling caretaking [and comments and reply]. Current Anthropology 18:169-190.

Whiting, B., and J. Whiting. 1975. Children of six cultures: a psycho-cultural analysis. Cambridge, MA: Harvard University Press.

Winking, J., M. Gurven, H. Kaplan, and J. Stieglitz. 2009. The goals of direct paternal care among a South Amerindian population. American Journal of Physical Anthropology 139:295-304. 